\title{
PENENTUAN RAINBOW CONNECTION NUMBER PADA HASIL OPERASI CARTESIAN PRODUCT TERHADAP GRAF LINGKARAN DAN GRAF BIPARTIT LENGKAP DENGAN GRAF LINTASAN
}

\author{
RESNITA YURI \\ Program Studi Matematika, \\ Fakultas Matematika dan Ilmu Pengetahuan Alam, Universitas Andalas, \\ Kampus UNAND Limau Manis Padang, Indonesia, \\ email : resnita.yuri12@gmail.com
}

\begin{abstract}
Abstrak. Misalkan terdapat graf terhubung taktrivial $G$. Jika setiap sisi-sisi $G$ diberi pewarnaan sehingga sebarang dua titik di $G$ dihubungkan oleh suatu lintasan yang memiliki warna berbeda disetiap sisi, maka $G$ disebut rainbow connected. Pewarnaan sisi dari $G$ ditulis $c: E(G) \rightarrow\{1,2, \cdots, k\} ; k \in \mathbb{N}$. Rainbow connection number dari graf $G$, dinotasikan dengan $\operatorname{rc}(G)$, adalah minimum dari banyaknya warna yang dibutuhkan untuk mewarnai $G$ sehingga $G$ rainbow connected. Cartesian product terhadap dua graf $G_{1}$ dengan $G_{2}$ dinotasikan dengan $G_{1} \times G_{2}$.

Dalam makalah ini akan dibahas kembali makalah [1] tentang penentuan bilangan rainbow connection dari graf $P_{n} \times K_{2,2}$ dan $P_{3} \times C_{n}$. Diperoleh bahwa $\operatorname{rc}\left(P_{n} \times K_{2,2}\right)=$ $n+1$ dan $r c\left(P_{3} \times C_{n}\right)=\left\lceil\frac{n}{2}\right\rceil+2$.

Kata Kunci: Graf lingkaran, Graf lintasan, Graf bipartit lengkap, Rainbow connection number
\end{abstract}

\section{Pendahuluan}

Misalkan $G$ adalah graf terhubung tak-trivial. Definisikan pewarnaan $c: E(G) \rightarrow$ $\{1,2, \cdots, k\} ; k \in \mathbb{N}$, dimana sisi $G$ yang bertetangga boleh memiliki warna yang sama. Suatu lintasan $u-v \in G$ dikatakan rainbow path jika tidak ada dua sisi pada lintasan yang memiliki warna sama. Graf $G$ dikatakan rainbow connected jika setiap dua titik yang berbeda di $G$ dihubungkan oleh rainbow path.

Dalam tulisan ini akan dibahas tentang rainbow connection number pada graf hasil operasi cartesian product antara graf lintasan dengan graf lingkaran, serta antara graf lintasan dengan graf bipartit lengkap $K_{2,2}$.

Misalkan terdapat graf terhubung $G$ dengan ukuran $m$. Ukuran $m$ menyatakan banyaknya sisi yang ada dalam graf $G$. Hubungan antara $\operatorname{diam}(G), \operatorname{rc}(G), \operatorname{src}(G)$ dan ukuran $m$ dijelaskan pada proposisi berikut.

Proposisi 1.1. [3] Misalkan $G$ adalah graf terhubung tak trivial berukuran $m$. Jika $c: E(G) \rightarrow\{1,2, \cdots, k\}, k \in \mathbb{N}$ merupakan pewarnaan rainbow coloring, maka

$$
\operatorname{diam}(G) \leq r c(G) \leq \operatorname{src}(G) \leq m
$$




\section{Rainbow Connection Number pada Hasil Operasi Cartesian Product Terhadap Graf Lingkaran dan Graf Bipartit Lengkap, dengan Graf Lintasan}

Pada Teorema 2.1 diberikan bilangan Rainbow Connection untuk graf hasil Cartesian Product graf bipartit lengkap $K_{2,2}$ dengan graf lintasan $P_{n}$, untuk $n \geq 2$.

Teorema 2.1. [1] Untuk $n \geq 2$, rainbow connection number untuk graf $\left(P_{n} \times K_{2,2}\right)$ adalah $n+1$.

Bukti. Perhatikan bentuk graf $P_{n} \times K_{2,2}$ pada Gambar 1 berikut. Dapat dilihat

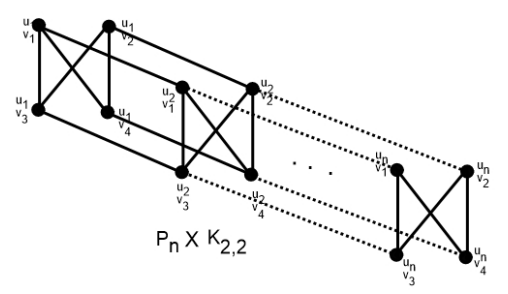

Gambar 1. Hasil operasi $P_{n} \times K_{2,2}$

bahwa graf $G \simeq P_{n} \times K_{2,2}$ mempunyai himpunan titik dan himpunan sisi sebagai berikut.

$$
\begin{aligned}
V\left(P_{n} \times K_{2,2}\right)= & \left\{a_{i}, b_{i}, c_{i}, d_{i} ; 1 \leq i \leq n\right\}, \\
E\left(P_{n} \times K_{2,2}\right)= & \left\{a_{i} b_{i}, a_{i} d_{i}, b_{i} c_{i}, c_{i} d_{i} ; 1 \leq i \leq n\right\} \\
& \bigcup\left\{a_{i} a_{i+1}, b_{i} b_{i+1}, c_{i} c_{i+1}, d_{i} d_{i+1} ; 1 \leq i \leq n-1\right\},
\end{aligned}
$$

dimana $a_{1}=u_{1} v_{1}, b_{1}=u_{1} v_{3}, c_{1}=u_{1} v_{2}, d_{1}=u_{1} v_{4}, a_{2}=u_{2} v_{1}, b_{2}=u_{2} v_{3}$, $c_{2}=u_{2} v_{2}, d_{2}=u_{2} v_{4}, \cdots, a_{n}=u_{n} v_{1}, b_{n}=u_{n} v_{3}, c_{n}=u_{n} v_{2}, d_{n}=u_{n} v_{4}$. Dapat dilihat bahwa $p=|V(G)|=4 n$ dan $q=|E(G)|=8 n-4$.

Selanjutnya ditentukan jarak masing-masing titik pada graf $P_{n} \times K_{2,2}$. Himpunan $d(x, y)$ dimana $x, y$ adalah sebarang titik pada graf $P_{n} \times K_{2,2}$ adalah $d(x, y)=\{1,2, \cdots, n+1\}$. Maka diperoleh bahwa

$$
\operatorname{diam}\left(P_{n} \times K_{2,2}\right)=\max \left\{d(x, y) \mid x, y \in V\left(P_{n} \times K_{2,2}\right)\right\}=n+1 .
$$

Karena $\operatorname{diam}\left(P_{n} \times K_{2,2}\right)=n+1$ maka

$$
r c\left(P_{n} \times K_{2,2}\right) \geq n+1 .
$$

Konstruksikan pewarnaan pada sisi-sisi graf $P_{n} \times K_{2,2}$, yang dapat dinyatakan dalam bentuk fungsi pewarnaan $c: E\left(P_{n} \times K_{2,2}\right) \rightarrow\{1,2, \cdots, n+1\}$ sebagai berikut.

$c(e)=\left\{\begin{array}{l}1, e=a_{i} v_{i} ; e=b_{i} u_{i} ; 1 \leq i \leq n, \\ 2, e=a_{i} b_{i} ; e=u_{i} v_{i} ; 1 \leq i \leq n, \\ j, e=a_{i} a_{i+1} ; e=b_{i} b_{i+1} ; e=u_{i} u_{i+1} ; e=v_{i} v_{i+1} ; 1 \leq i \leq n-1 ; 3 \leq j \leq n+1 .\end{array}\right.$ 
Berdasarkan pewarnaan tersebut diperoleh bahwa

$$
r c\left(P_{n} \times K_{2,2}\right) \leq n+1 .
$$

Dari (2.1) dan (2.2) diperoleh bahwa $\operatorname{rc}\left(P_{n} \times K_{2,2}\right)=n+1$.

Pada Teorema 2.2 diberikan bilangan Rainbow Connection untuk graf hasil Cartesian Product graf lingkaran $C_{n}$ dengan graf lintasan $P_{3}$, untuk $n \geq 3$.

Teorema 2.2. [1] Untuk $n \geq 3$, rainbow connection number untuk graf $\left(P_{3} \times C_{n}\right)$ adalah $\left\lceil\frac{n}{2}\right\rceil+2$.

Bukti. Perhatikan bentuk graf $P_{3} \times C_{n}$ pada Gambar 2 berikut.

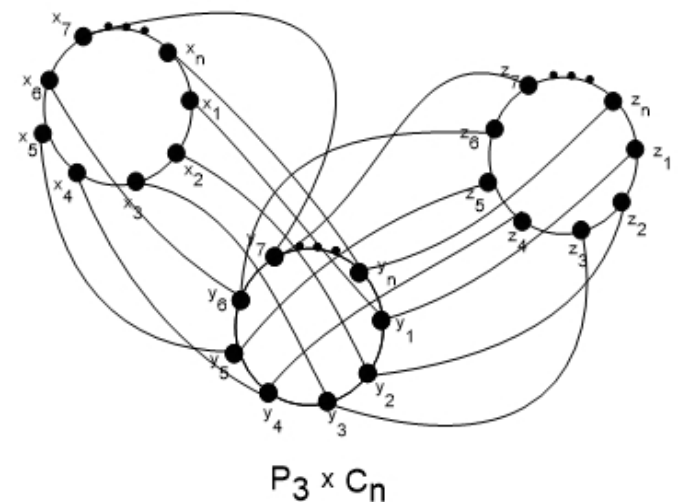

Gambar 2. $P_{3} \times C_{n}$

Misalkan $V\left(P_{3}\right)=\left\{u_{1}, u_{2}, u_{3}\right\}$ dan $V\left(C_{n}\right)=\left\{v_{1}, v_{2}, \cdots, v_{n}\right\}$. Maka graf $H \simeq$ $P_{3} \times C_{n}$ mempunyai himpunan titik dan himpunan sisi sebagai berikut.

$$
\begin{aligned}
V\left(P_{3} \times C_{n}\right)= & \left\{a_{i}, b_{i}, c_{i} ; 1 \leq i \leq n\right\}, \\
E\left(P_{3} \times C_{n}\right)= & \left\{a_{i} b_{i}, b_{i} c_{i} ; 1 \leq i \leq n\right\} \bigcup\left\{a_{i} a_{i+1}, b_{i} b_{i+1}, c_{i} c_{i+1} ; 1 \leq i \leq n-1\right\} \\
& \bigcup\left\{a_{n} a_{1}, b_{n} b_{1}, c_{n} c_{1}\right\},
\end{aligned}
$$

dimana $a_{1}=u_{1} v_{1}, b_{1}=u_{2} v_{1}, c_{1}=u_{3} v_{1}, a_{2}=u_{1} v_{2}, b_{2}=u_{2} v_{2}, c_{2}=u_{3} v_{2}$, $\cdots, a_{n}=u_{1} v_{n}, b_{n}=u_{2} v_{n}, c_{n}=u_{3} v_{n}$. Dapat dilihat bahwa $p=|V(H)|=3 n$, $q=|E(H)|=5 n$.

Selanjutnya ditentukan jarak masing-masing titik pada graf $P_{3} \times C_{n}$. Himpunan $d(x, y)$ dimana $x, y$ adalah titik sebarang pada graf $P_{3} \times C_{n}$ adalah $d(x, y)=$ $\left\{1,2, \cdots,\left\lceil\frac{n}{2}\right\rceil+2\right\}$. Maka diperoleh bahwa

$$
\operatorname{diam}\left(P_{3} \times C_{n}\right)=\max \left\{d(x, y) \mid x, y \in V\left(P_{3} \times C_{n}\right)\right\}=\left\lceil\frac{n}{2}\right\rceil+2 .
$$


Karena $\operatorname{diam}\left(P_{3} \times C_{n}\right)=\left\lceil\frac{n}{2}\right\rceil+2$ maka

$$
r c\left(P_{n} \times K_{2,2}\right) \geq\left\lceil\frac{n}{2}\right\rceil+2 .
$$

Konstruksikan pewarnaan pada sisi-sisi graf $P_{3} \times C_{n}$, yang dapat dinyatakan dalam bentuk fungsi pewarnaan $c: E\left(P_{3} \times C_{n}\right) \rightarrow\left\{1,2, \cdots,\left\lceil\frac{n}{2}\right\rceil+2\right\}$ sebagai berikut.

$$
c(e)=\left\{\begin{aligned}
i, \quad e & =a_{i} a_{i+1} ; e=b_{i} b_{i+1} ; e=c_{i} c_{i+1} ; 1 \leq i \leq\left\lceil\frac{n}{2}\right\rceil, n \text { genap, } \\
e & =a_{\left\lceil\frac{n}{2}\right\rceil+i} a_{\left\lceil\frac{n}{2}\right\rceil+i+1} ; e=b_{\left\lceil\frac{n}{2}\right\rceil+i} b_{\left\lceil\frac{n}{2}\right\rceil+i+1} ; e=c_{\left\lceil\frac{n}{2}\right\rceil+i} c_{\left\lceil\frac{n}{2}\right\rceil+i+1}, \\
1 & \leq i \leq\left\lceil\frac{n}{2}\right\rceil-1, n \text { genap, } \\
e & =a_{i} a_{i+1} ; e=b_{i} b_{i+1} ; e=c_{i} c_{i+1} ; 1 \leq i \leq\left\lceil\frac{n}{2}\right\rceil-1, n \text { ganjill, } \\
e & =a_{\left\lceil\frac{n}{2}\right\rceil+i-1} a_{\left\lceil\frac{n}{2}\right\rceil+i} ; e=b_{\left\lceil\frac{n}{2}\right\rceil+i-1} b_{\left\lceil\frac{n}{2}\right\rceil+i} ; e=c_{\left\lceil\frac{n}{2}\right\rceil+i-1} c_{\left\lceil\frac{n}{2}\right\rceil+i}, \\
1 & \leq i \leq\left\lceil\frac{n}{2}\right\rceil-2, n \text { ganjil, } \\
\left\lceil\frac{n}{2}\right\rceil-1, e & =a_{n-1} a_{n} ; e=b_{n-1} b_{1} ; c_{n-1} c_{n} ; \\
\left\lceil\frac{n}{2}\right\rceil, \quad & =a_{n} a_{1} ; e=b_{n} b_{1} ; e=c_{n} c_{1}, \\
\left\lceil\frac{n}{2}\right\rceil+1, e & =a_{i} b_{i} ; 1 \leq i \leq n, \\
\left\lceil\frac{n}{2}\right\rceil+2, e & =b_{i} c_{i} ; 1 \leq i \leq n .
\end{aligned}\right.
$$

Berdasarkan pewarnaan tersebut diperoleh bahwa

$$
r c\left(P_{3} \times C_{n}\right) \leq\left\lceil\frac{n}{2}\right\rceil+2 .
$$

Dari (2.1) dan (2.2) diperoleh bahwa $r c\left(P_{3} \times C_{n}\right)=\left\lceil\frac{n}{2}\right\rceil+2$.

Pewarnaan pada $\left(P_{3} \times C_{5}\right)$ dapat dilihat pada Gambar 3 .

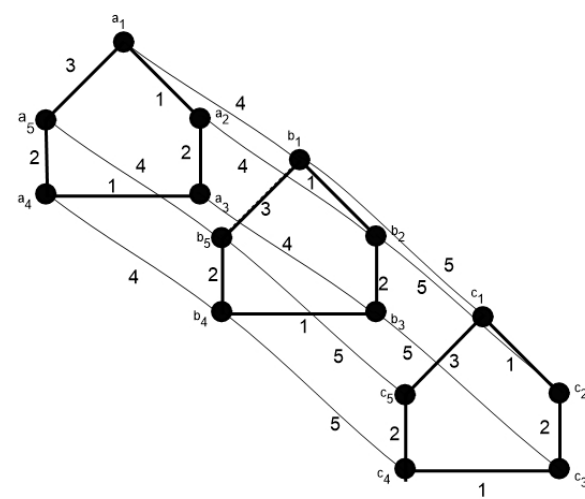

Gambar 3. $r c\left(P_{3} \times C_{5}\right)$

Pewarnaan pada $\left(P_{3} \times C_{6}\right)$ dapat dilihat pada Gambar 4 .

\section{Kesimpulan}

Pada makalah ini telah dibahas kembali makalah [1] tentang penentuan bilangan rainbow connection dari graf $P_{n} \times K_{2,2}$ dan $P_{3} \times C_{n}$. Diperoleh bahwa $r c\left(P_{n} \times K_{2,2}\right)=$ $n+1$ dan $r c\left(P_{3} \times C_{n}\right)=\left\lceil\frac{n}{2}\right\rceil+2$. 


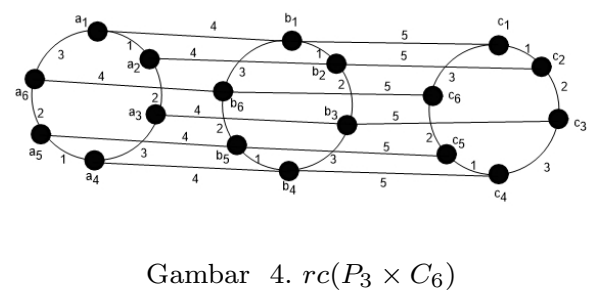

\section{Ucapan Terima Kasih}

Penulis mengucapkan terima kasih kepada Bapak Prof. Dr. Syafrizal Sy, Bapak Dr. Effendi, Ibu Dr. Lyra Yulianti, Bapak Narwen, M.Si, dan Bapak Dr. Admi Nazra, yang telah memberikan masukan dan saran sehingga makalah ini dapat diselesaikan dengan baik.

\section{Daftar Pustaka}

[1] Arnasyitha, Yulianti. dan Dafik. Rainbow Connection Number Pada Operasi Graf. Prosiding Seminar Nasional Matematika 2014. Universitas Jember, hal. $83-87$

[2] Bondy, J. A. dan U. S. R. Murty. 1976. Graph Theory with Applications. Macmillan. London

[3] G. Chartrand, G.L. Johns, K.A. McKeon, dan P. Zhang. 2008. Rainbow connection in graphs. Math. Bohem., 133(2) : $85-98$

[4] Darmawan, R. N. 2015. Analisis Rainbow Connection Number pada Graf Khusus dan Hasil Operasinya. Tesis S-2, tidak diterbitkan, Universitas Jember. Jember

[5] Harary, F. 1970. Graph Theory. Wesley Publishing Company. London

[6] Kitaev, S. dan Lozin,V. 2015. Words and Graphs. Springer. New York

[7] Li, Xueliang, and Liu, Sujuan, Rainbow Connection Number and Connectivity. 2012. The Electronic Journal of Combinatorics 19 : P20

[8] Li, X. dan Sun, Y.2012. Rainbow Connection of Graphs. Springer. New York. 